\title{
Heterotopic pregnancy: case report of a successful first trimester metacyesis management and a viable third trimester outcome
}

\author{
Arvind Kumar Singh ${ }^{1}$, Shazia Khan ${ }^{2 *}$
}

\author{
${ }^{1}$ Department of Surgery, INHS Jeevanti, Goa, India \\ ${ }^{2}$ Department of Obstetrics and Gynecology, INHS Asvini, Mumbai, Maharashtra, India
}

Received: 06 November 2018

Accepted: 13 December 2018

\section{*Correspondence:}

Dr. Shazia Khan,

E-mail: drshaziakhan@gmail.com

Copyright: (C) the author(s), publisher and licensee Medip Academy. This is an open-access article distributed under the terms of the Creative Commons Attribution Non-Commercial License, which permits unrestricted non-commercial use, distribution, and reproduction in any medium, provided the original work is properly cited.

\begin{abstract}
Heterotopic pregnancies are rare combined intra and extrauterine pregnancies, the incidence of which has shown an increase over the past decade with the rising trend in assisted reproductive technologies $(0.75-1.5 \%)$. Authors report a case of a 29 year old primigravida, a post IVF conception who presented at 6 weeks POG with a ruptured tubal and a viable intrauterine pregnancy. She underwent an emergency laparoscopic right salpingectomy and continued with her intrauterine pregnancy successfully till term. The article emphasizes the need of scanning the adnexa carefully in early pregnancy to diagnose and manage heterotopic pregnancy as early as possible to prevent catastrophic haemorrhage and maternal morbidity and mortality later.
\end{abstract}

Keywords: Heterotopic, Hemoperitoneum, Laparoscopic salpingectomy, Metacyesis

\section{INTRODUCTION}

The earlier dictum in medical school and residency was to be ectopic minded. With the assisted reproductive technologies going rampant the spectrum now is shifting towards being heterotopic minded.

Heterotopic pregnancy is the coexistence of intra and extrauterine pregnancies. The incidence has been estimated to be about 1 in 30,000 spontaneous pregnancies. With the use of assisted reproductive technologies, the incidence is as high as $0.75 \%$ to $1.5 \%$ of pregnancies. ${ }^{1}$ In 1708, Duverney reported an incidental finding of noting an intrauterine pregnancy while performing the autopsy on a patient who had died of haemorrhage due to a ruptured ectopic pregnancy. ${ }^{2}$ The ampulla is the most common site representing $70 \%$ of the ectopic pregnancies, followed by fimbria (12\%), isthmus $(11 \%)$, interstitial $(2-3 \%)$, ovary $(1 \%)$, scar ectopic $(1 \%)$, cervical and abdominal ectopic $(1 \%){ }^{2}$ Surgery with laparoscopic salpingectomy with minimal or no uterine manipulation remains the main modality for managing the ectopic with evacuation of hemoperitoneum subsequently. Two thirds of intrauterine pregnancies carry on till term with or without progesterone support. Authors present a case of heterotopic pregnancy managed successfully with a favourable maternal and fetal outcome.

\section{CASE REPORT}

A 29-year-old Primigravida, conceived after IVF presented to gynae OPD with complaints of pain abdomen and giddiness of 4 hours duration. There was no history of per vaginal bleeding, nausea, trauma, bladder or bowel symptoms or any drug intake. On clinical examination patient was anxious with mild pallor, mildly tachycardic with pulse of 100/min and BP-90/60 mm of $\mathrm{Hg}$. Her abdomen was soft with mild distension and there was diffuse tenderness on palpation. Guarding was present over lower abdomen and no abdominal mass was palpable. Her LMP was on 16 July 2017 and ET was 
done on $4^{\text {th }}$ August 2017. A per vaginal examination showed a cervical length of $2.8 \mathrm{~cm}$ with right forniceal tenderness and fullness. Trans vaginal USG showed a mass of $1.2 \times 1.5 \mathrm{~cm}$ arising from right fallopian tube with hemorrhagic fluid collection in pelvis (Figure1) and bilateral paracolic gutters (approximately 1.5 liters) along with a single live intrauterine pregnancy with CRL corresponding to 6 weeks 4 days.

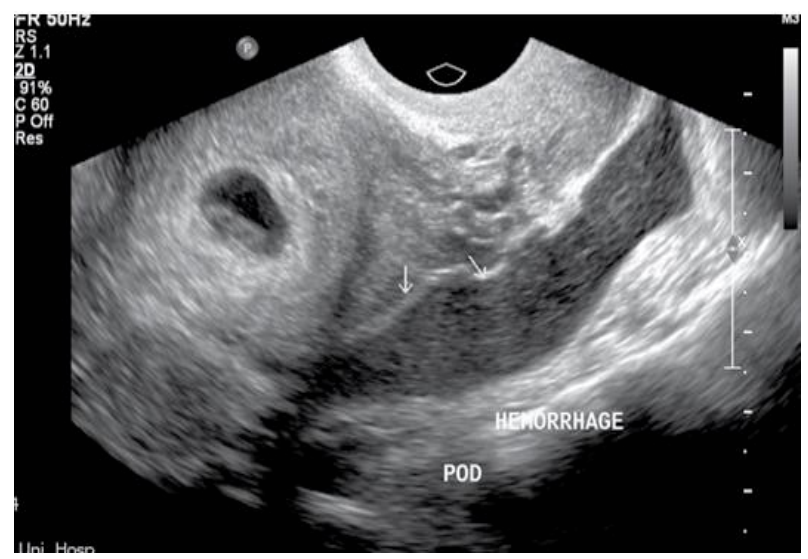

Figure 1: Transvaginal ultrasound showing a viable intrauterine pregnancy with POD collection of hemorrhagic fluid.

A diagnosis of heterotopic pregnancy with ruptured tubal ectopic was made. Her $\mathrm{Hb}$ on admission was $10 \mathrm{~g} / \mathrm{dl}$ and PCV 28\% (A fall noted from previous $\mathrm{Hb}$ of $16 \mathrm{~g} / \mathrm{dl}$ taken 2 weeks back on confirmation of pregnancy). She was taken up for Emergency Diagnostic Laparoscopy and proceed under GA after written and informed consent regarding risk to her and the viable pregnancy was taken.

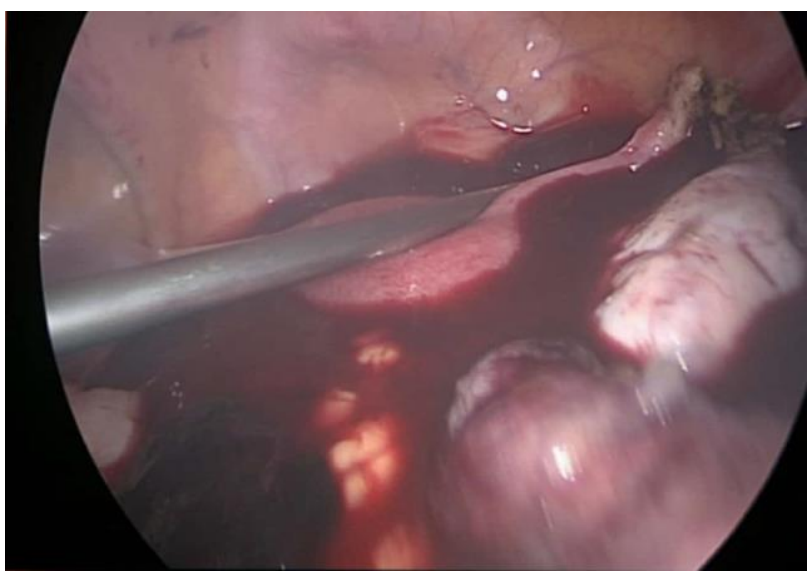

Figure 2: Laparoscopy revealed hemoperitoneum of around 1.5litres.

No vaginal manipulator was used. Intra op 1.5liter of hemorrhagic fluid (containing blood clot and fresh blood) (Figure 3) and a mass $1 \times 1.5 \mathrm{~cm}$ (approx.) arising from ampulla of the right fallopian tube with active bleeding was noted. Right salpingectomy was done. (Figure 4) The specimen was sent for histopathology. Complete hemostasis was achieved, and a thorough abdominal lavage was given with 3 liters of Luke warm saline.

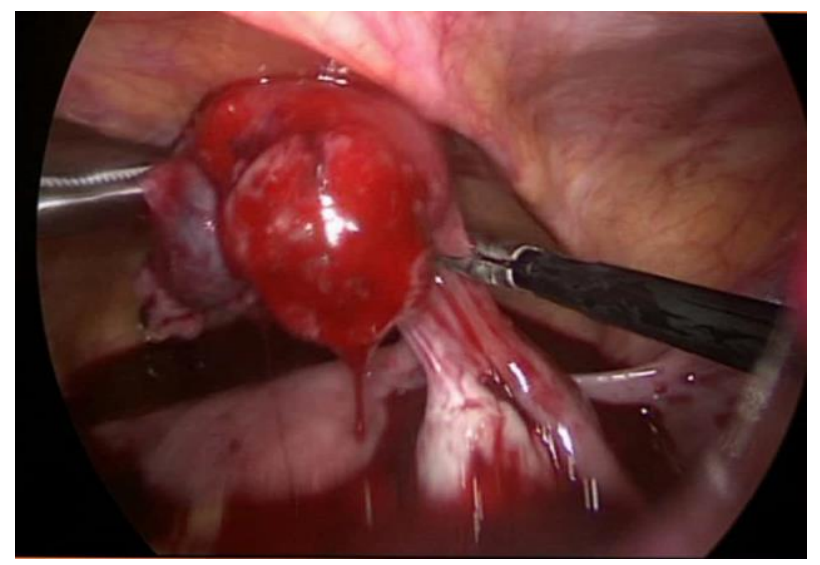

Figure 3: Ruptured right tubal ampullary ectopic of $1 \times 1.5 \mathrm{~cm}$ size.

A 16 Fr drain was placed in POD. Post op period was uneventful with a $\mathrm{Hb}$ of $9.6 \mathrm{~g} / \mathrm{dl}$ and viability of intrauterine pregnancy of 7 weeks was confirmed on USG. The histopathology report was consistent with ampullary ectopic. She was discharged with a single intrauterine live pregnancy on 5th post op day. She was counselled about risks of abortion and preterm labour associated with the procedure performed. She continued to be on regular follow up with sustained progesterone support, in the ANC OPD and she delivered vaginally at 39 weeks a healthy male child of $2.9 \mathrm{~kg}$.

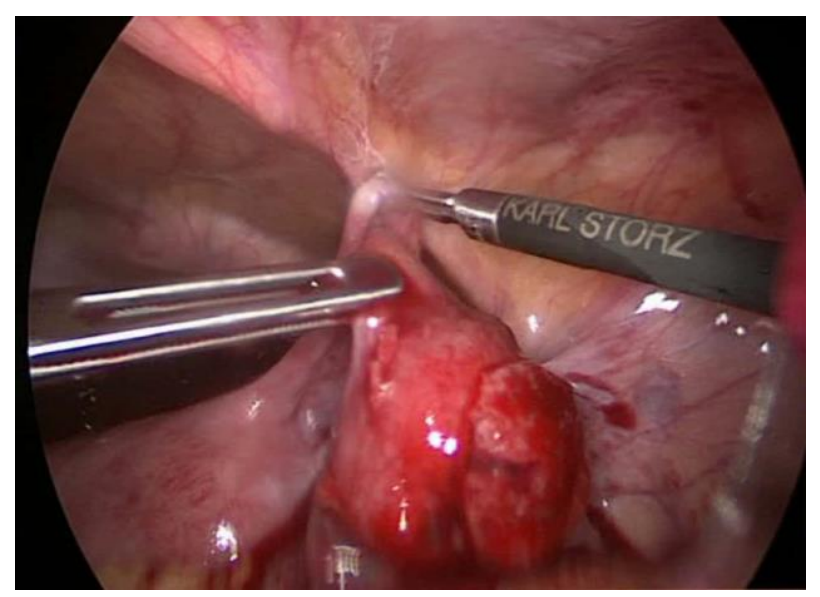

Figure 4: Right laparoscopic salpingectomy done.

\section{DISCUSSION}

The use of ovulation-inducing agents has increased the incidence of multiple gestations and heterotopic pregnancies. Berger and Taymor reported an incidence of combined pregnancy in as many as 1 in 100 stimulated patients. With clomiphene citrate the incidence is 1 in 900 whereas with gonadotrophins it is $1 \% .^{3}$ The most common predisposing anatomic finding associated with heterotopic pregnancies is preexisting tubal disease. ${ }^{4}$ 
Abdominal pain, adnexal mass and an enlarged uterus constitute the major clinical features associated with a heterotopic pregnancy. Unlike sole ectopic pregnancies which are diagnosed and managed early, heterotopic pregnancies are still mostly diagnosed after clinical signs of rupture, hemorrhage or maternal collapse manifest. This is due to the fact that serial $\beta$-hCG determinations and transvaginal ultrasonography are often not helpful in establishing an early diagnosis. ${ }^{3-5}$ And usually the delay is due to inability of treating clinician to think of a heterotopic pregnancy once an intrauterine gestation is established. ${ }^{6}$ They are often confused with ruptured corpus luteum cyst. In present case the diagnosis was made when patient presented with rupture of the ectopic pregnancy.

The aim of management of heterotopic pregnancy should be to offer the least invasive method for a favorable outcome of the intrauterine pregnancy. ${ }^{7}$ While systemic medical management is absolutely contraindicated in the presence of a viable intrauterine pregnancy, surgical management remains the recommended cornerstone of treatment. A laparoscopic approach is preferred in view of better visualization and faster post-operative recovery. ${ }^{8}$ In cases in which hemodynamic instability or an interstitial-intrauterine pregnancy is present, a laparotomy is indicated. Expectant management plays no role in the care of a patient with a heterotopic pregnancy. This is due to the fact that the specific course of the extrauterine component becomes difficult to be monitored by serial $\beta$ hCG determinations. Also, either local or systemic MTX therapy would be contraindicated in view of a viable intrauterine gestation. The use of a local injection of potassium chloride into the extrauterine gestational sac, however, has been used successfully in a few cases. ${ }^{9}$ There are very rare cases in which extrauterine abdominal pregnancies progress simultaneously with intrauterine pregnancies to viability. In their review of the world's literature, Reece and associates found only 13 cases in which both pregnancies reached term and both infants were delivered and survived the neonatal period. ${ }^{1,10}$

\section{CONCLUSION}

With heterotopic pregnancies becoming more common, it becomes essential to be able to identify and manage these patients early in pregnancy before any catastrophic presentation. It thus becomes essential to be thorough while doing the early ultrasound and scanning the adnexa in all pregnancies. Timely detection and management will aid in decreasing the maternal morbidity and also ensuring a viable outcome for the intrauterine gestation.
Funding: No funding sources

Conflict of interest: None declared

Ethical approval: Not required

\section{REFERENCES}

1. Damario MA. Ectopic Pregnancy. Chapter 34. Te Lindes' Operative Gynaecology. Lippincott Williams and Wilkins. $11^{\text {th }}$ ed; 2015:794-795.

2. Bright DA, Gaupp FB. Heterotopic pregnancy: a reevaluation. J Am Board Family Practice. 1990;3(2):125-8.

3. Wallach EE, Tal J, Haddad S, Gordon N, TimorTritsch I. Heterotopic pregnancy after ovulation induction and assisted reproductive technologies: a literature review from 1971 to 1993. Fertil Steril. 1996;66(1):1-2.

4. Hassani K, El Bouazzaoui A, Khatouf M, Mazaz K. Heterotopic pregnancy: A diagnosis we should suspect more often. J Emerg Trauma Shock. 2010;3(3):304.

5. Kumar R, Dey M. Spontaneous heterotopic pregnancy with tubal rupture and pregnancy progressing to term. Med $\mathbf{J}$ Armed Forces Ind. 2015;71:S73-5.

6. Talbot K, Simpson R, Price N, Jackson SR. Heterotopic pregnancy. J Obstet Gynaecol. 2011;31(1):7-12.

7. Tsakos E, Tsagias N, Dafopoulos K. Suggested method for the management of heterotopic cervical pregnancy leading to term delivery of the intrauterine pregnancy: Case report and literature review. J Minimally Invasive Gynecol. 2015;22(5):896-901.

8. Louis-Sylvestre C, Morice P, Chapron C, Dubuisson JB. The role of laparoscopy in the diagnosis and management of heterotopic pregnancies. Hum Reprod (Oxford, England). 1997;12(5):1100-2.

9. Goldstein JS, Ratts VS, Philpott T, Dahan MH. Risk of surgery after use of potassium chloride for treatment of tubal heterotopic pregnancy. Obstet Gynecol. 2006;107(2):506-8.

10. Reece EA, Petrie RH, Sirmans MF, Finster M, Todd WD. Combined intrauterine and extrauterine gestations: a review. Am J Obstet Gynecol. 1983;146(3):323-30.

Cite this article as: Singh AK, Khan S. Heterotopic pregnancy: case report of a successful first trimester metacyesis management and a viable third trimester outcome. Int J Reprod Contracept Obstet Gynecol 2019;8:332-4. 